\title{
NIETZSCHE, Friedrich. Sobre a utilidade e a desvantagem da história para a vida. Tradução de André Luís Mota Itaparica. São Paulo: Hedra, 2017.
}

José Nicolao Julião*

O ensaio de Nietzsche Vom Nutzen und Nachteil der Historie für das Leben apareceu ao grande público, em fevereiro de 1874, como a segunda parte de uma ambiciosa obra intitulada Unzeitgemässe Betrachtungen, cuja primeira parte, David Strauss der Bekenner und der Schriftsteller, publicada no ano anterior, havia feito grande sucesso de vendagem, exigindo uma segunda edição, no mesmo ano de sua publicação, sobretudo devido à polêmica matéria enfurecida que o periódico Grenzboten, em sua edição de outubro de 1873 (ano 32, $2^{\circ}$ semestre, $2^{\circ}$ volume, p. 104-110), com o título "Herr Nietzsche und die deutsche Cultur", havia lançado contra ela.

\footnotetext{
* Professor titular da UniversidadeFederal Rural do Rio de Janeiro, Rio de Janeiro, Brasil, Brasil. Pesquisador 2 do CNPq.

Correio eletrônico: jnjnicolao@gmail.com
} 
Julião, J. N.

A mesma audiência, contudo, não alcançou de imediato a segunda das Extemporâneas, retumbando sobre ela um sonoro silêncio ${ }^{1}$, para depois tornar-se uma das mais conhecidas obras de seu autor e talvez umas das mais influentes no âmbito das Ciências Humanas. Herbert Schnädelbach considera esse ensaio de Nietzsche como o primeiro documento crítico ao Historicismo alemão²; Karl Schlechta diz o seguinte sobre o tratado: "Nele, o 'Historicismo' toma consciência dele mesmo de forma assustadora : o diagnóstico do autor foi tão sombrio que foi necessário familiarizar-se com esse estado de risco doentio"3. O filólogo Karl Reinhardt considerou que o Historicismo foi tão depreciado que fica difícil que se possa achar ainda algo a dizer contra ele ${ }^{4}$. Fora o impacto crítico ou devido a ele, como chama atenção o tradutor André Itaparica, na sua aguda introdução à sua cautelosa tradução, há também o destaque que o ensaio ganhou em obras já consagradas sobre a filosofia de Nietzsche, como nos livros de Karl Jaspers (Nietzsche, Einführung in das Verständnis seines Philosophierens - 1946) e Walter Kaufmann (Nietzsche: Philosopher, Psychologist, Antichrist - 1956), podemos adicionar a essa lista, entre aqueles que reconhecem o valor da Segunda Extemporânea e já se tornaram consagrados, Müller-Lauter (Nietzsche, Seine Philosophie der Gegensätze und die Gegensätze seiner Philosophie - 1971) e Michel Foucault ("Nietzsche, Freud, Marx" - 1967 - e "Nietzsche, la genealogie, l'histoire" - 1971). Itaparica menciona ainda o seminário ministrado por Heidegger, no semestre de inverno de 1938-39, dedicado à

1 Karl Hillebrand, ex-secretário de Heine, quem Nietzsche cita em $E H(C f . E H / E H$. As Extemporâneas, 1, KSA 6.318), devido a sua resenha favorável à Extemporânea I, publicada no Allegemeine Zeitung Augsburg, número 256-266, setembro de 1873, p. 256-266, publicou, depois, comentários às três primeiras Extemporâneas, na coletânea Zeiten, Völker und Mennschen. Strassburg, 1892, mas escrito em 1874-5. Nada indica que Nietzsche tenha conhecido o teor dos comentários à segunda e à terceira das suas Extemporâneas.

2 Cf. Filosofía en Alemania (1831-1933). Trad. Española. Madrid: Ediciones Cátedras, 1991, p. 81.

3 Cf. Der Fall Nietzsche: Aufsätze und Vorträge. 2. Auflage. München : Hanser, 1959, p. 44. (“Nietzsches verhältnis zur Historie").

4 Cf. Von Werken und Formen. Godesberg, 1948, p.432,

$180 \mid$ Cad. Nietzsche, Guarulhos/Porto Seguro, v.38, n.2, p. 179-186, maio/agosto, 2017. 
NIETZSCHE, Friedrich. Sobre a utilidade e a desvantagem ...

Extemporânea II (publicado no volume 46, da edição crítica: Zur Auslegung von Nietzsches II. Unzeitgemässer Betrachtung. In: Martin Heidegger Gesamtausgabe (HG. 46), Frankfurt: Vittorio Klostermann, 2005) para dar visibilidade à dimensão da projeção e fecundidade do texto nietzschiano. Neste assunto, nós nos deteremos um pouco mais para estabelecermos um contraponto à nossa compreensão do texto traduzido impecavelmente por André Itaparica.

No seminário, Heidegger retoma e desenvolve teses já apresentadas, incipientemente, em 1927, no parágrafo 76 de Ser e Tempo, intitulado Der existenziale Ursprung der Historie aus der Geschichtlichkeit des Dasein, nas quais ele mostra a partir de Nietzsche que o homem é essencialmente histórico, entretanto, cabe saber até que ponto a história é útil ou prejudicial à vida, tema central, que deve ser compreendido, como a experiência da vida humana, que só pode ser pensada no interior de uma cultura. No que concerne ao seminário, Heidegger, já na introdução, previne que a concepção ampla e ambígua do projeto lhe garante certa liberdade interpretativa, propondo, em seguida, uma divisão do estudo em três partes: "Grosso modo, o trabalho que nos propomos contém três partes: 1. Introdução à formação conceitual filosófica, 2. mas isto, como leitura e interpretação para um tratado definitivo e, consequentemente, 3 . na abordagem da filosofia de Nietzsche." Ele também deixa claro de imediato que não escolheu Nietzsche por moda, mas porque ele foi "o último pensador da história da filosofia ocidental, isto é, da metafísica: pensar o seu pensamento é, ao mesmo tempo, levar a filosofia ocidental em suas linhas básicas ao primeiro patamar do saber"6. Heidegger, embora não se expresse de forma tão clara na escolha da Segunda Extemporânea como tema para o seminário, no entanto, ele sugere que o trabalho lhe apresenta uma oportunidade especial para ilustrar a posição de Nietzsche na história da metafísica. A análise do

5 HGA 46, 3.

6 Cf. HGA 46, 6.

Cad. Nietzsche, Guarulhos/Porto Seguro, v.38, n.2, p. 179-186, maio/agosto, 2017. $\mid 181$ 
Julião, J. N.

tratado, para ele, tampouco se limita a uma mera interpretação, mas fornece uma justificação permanente para compreensão da posição de Nietzsche dentro da totalidade da tradição filosófica. O Filósofo da Floresta Negra procede, todavia, em conformidade, no decorrer do seminário, estabelecendo uma diferença entre a consideração científica e pensamento filosófico, ou seja, entre a conceituação científica e filosófica na orientação da análise do conceito de "vida" em Nietzsche. Desse modo, a interpretação é guiada pela hipótese de que "vida" é a leitwort da Segunda Extemporânea, assim como de toda a filosofia de Nietzsche ${ }^{7}$. Mas, segundo o autor de Ser e Tempo, o conceito de "vida" é ambíguo em Nietzsche, pois significa o ser em sua totalidade e o modo de ser do ser particular, cuja vida é a humana. O ser compreendido como o ser humano, como em toda a tradição filosófica, a metafísica não é superada, porém ratificada. Para Heidegger, o homem continua sendo um animal racional: a única novidade é a ênfase dada à corporalidade , mas que, para ele, não é suficiente para se ir além de Descartes. A concepção do sujeito como ego vivo ${ }^{\mathbf{8}}$ é a justificação como o mais alto representante da vida e da verdade como um erro necessário da vida, que Heidegger atribui a Nietzsche, contudo é válido apenas como conclusão da metafísica moderna, ou como uma (possível) transição para outro começo, mas não como um (real) outro começo", e é por isso que ele afirma: "A principal questão sobre a Segunda Consideração Extemporânea de Nietzsche não é a desvantagem ou a utilidade da história, mas a compreensão da vida como a realidade básica no sentido de uma biologia cultural "10. Para ele, Nietzsche não consegue a superação da metafísica nem uma investigação detalhada da história, porque

7 Cf. HGA 46, 108

8 Cf. HGA 46, $142 \mathrm{ss.}$

9 Este seminário é contemporâneo à elaboração da obra Beiträgen zur Philosophie (Vom Ereignis), entre 1936 e 1938, e que só foi publicada postumamente, na qual Heidegger propõe a transição de Ser e Tempo para um "outro começo", expressão muito utilizada por ele na época.

10 HGA 46, 255.

182 | Cad. Nietzsche, Guarulhos/Porto Seguro, v.38, n.2, p. 179-186, maio/agosto, 2017. 
NIETZSCHE, Friedrich. Sobre a utilidade e a desvantagem ...

ele não pensou a históri da História , isto é, a essência do homem, e a sua relação com a verdade do ser.

Na nossa compreensão, a interpretação esquemática de Heidegger, tão entusiasmadamente defendida pelos heideggerianos, para analisar a história da filosofia a partir da sua Seinsgeschichte, reduzindo-a à história da metafísica, não é satisfatória para a análise da Segunda Extemporânea. Atualmente, na Nietzscheforschung, a interpretação dominante desse ensaio tende a arrefecer justamente a carga metafísica do texto nietzschiano, tão enfatizada por Heidegger, mesmo que ainda sobre ele reverbere teses metafísicas da obra inaugural. Em o Nascimento da Tragédia, Nietzsche havia se posicionado radicalmente crítico em relação à infecundidade criativa do que então chamou de metafísica racional, caracterizada pela crença otimista na capacidade da razão em alcançar um conhecimento objetivo que consolaria o ser humano da sua condição de finitude e fraqueza, e, como alternativa, defendeu também uma "metafísica de artista" em que valoriza os efeitos ilusórios e criativos da arte como forma superior de compreensão do mundo. A repercussão da crítica à metafísica racional na Segunda Extemporânea recai sobre o tratamento caudal científico da historiografia como um rebento moderno da racionalização humana. Portanto, o diagnóstico de que os males da cultura se devem à hipertrofia do sentido histórico apresentado nesse tratado depende da tese peculiar do Nascimento da Tragédia, segundo a qual há na modernidade uma hipertrofia dos impulsos cognitivos que impossibilita uma cultura realmente autêntica e elevada. Por isso, para Nietzsche, os interesses teóricos predominaram sobre quaisquer outros interesses, produzindo, consequentemente, um desequilíbrio vital que ele, em oposição, apresentou como superior o caráter criativo e ilusório da arte. É nesse sentido que ele propõe, na segunda de suas Extemporâneas, uma escrita da história como recriação artística do passado, que pode ser compreendida como a "força plástica", como alternativa à 
tendência racionalista, predominante na historiografia alemã de sua época, sem, contudo, recorrer à própria metafísica, como fez na obra inaugural. Argumentando a respeito de como seria possível medir até que ponto é salutar lembrar e em que momento é vital esquecer, Nietzsche descreve o conceito de força plástica, diz ele:

A fim de determinar esse grau e, por meio dele, o limite do que deve ser esquecido, para que o passado não se torne o coveiro do presente, se deveria saber exatamente quão grande é a força plástica de um homem, de um povo, de uma cultura, quero dizer, aquela força que cresce a partir de si mesma, transformando e incorporando o passado e o estranho, curando feridas, restabelecendo o perdido, reconstituindo por si mesma formas arruinadas (HL/Co. Ext. II, KSA 1.251).

Portanto, como capacidade de assimilação e resignação em relação ao passado como perda e alteridade, a força plástica habilita a memória a lembrar e esquecer, na exata medida, sem sobrecarregarse de lembranças.

Nietzsche está, portanto, na busca de um saber filosófico que não seja nem filosofia da história nem história universal tal como já havia rejeitado Burckhardt nas primeiras linhas de suas Considerações sobre história universal:

Nós nos abstraímos de toda sistemática; não revindicamos nenhuma "ideia de história universal", contentaremos em registrar nossas percepções e realizar uma série de cortes transversais ao longo da história na maior quantidade possível de direções; nós não oferecemos aqui nenhuma filosofia da história . Esta é um centauro, uma contradictio in adjecto, pois a história que coordena é a negação da filosofia, enquanto a filosofia que subordina é a negação da história. ${ }^{11}$

11 Cf. Weltgeschichtliche Betrachtungen. 2. Ausgabe. Berlin/Stuttgart: Verlag W. Spmann, 1910, p. 2. Embora, a primeira edição dessa obra seja 1905, trata-se das Vorlesungen de 1870-1871, ministradas em Basel e que Nietzsche havia assistido.

$184 \mid$ Cad. Nietzsche, Guarulhos/Porto Seguro, v.38, n.2, p. 179-186, maio/agosto, 2017. 
NIETZSCHE, Friedrich. Sobre a utilidade e a desvantagem ...

Ele busca uma base a partir da qual seja possível um saber que vincule a orientação à ação, pois nem a metafísica e nem a ciência compreendida como ciência histórica -, podem mais oferecer tal nexo.

A tradução que André Itaparica apresenta de Sobre a utilidade e a desvantagem da história para a vida, recém-publicada pela editora paulista Hedra, ao público de língua portuguesa, sem querer desmerecer as outras, que são meritórias em diversos aspectos, é a mais completa e bem sucedida tradução desse tratado de Nietzsche que nos permitirá um grande avanço, renovando as pesquisas, possibilitando outras compreensões que nos desamarrem das antigas e viciadas interpretações. Elaborada com acribia, a tradução soluciona alguns problemas sintáticos que dificultavam a compreensão semântica de diversas passagens, consolida também o estabelecimento de alguns termos chaves, como, por exemplo, o mais emblemático, Unzeitgemässe, como extemporâneas que era frequentemente traduzido, nas traduções anteriores, como intempestivas e, ainda, nos oferece um grande número de notas esclarecedoras. Sabemos que toda tradução é uma atividade árdua e desgastante, nem sempre reconhecida quando acertada e bastante criticada toda vez que mal executada. A princípio, para traduzir um texto não basta simplesmente transferir as palavras de uma língua para outra, tem de ter a capacidade de interpretar o significado de um texto em uma língua e a produção de outro texto em outra língua, mas que exprima o texto original da forma mais exata possível na língua de destino, mesmo que recaia sobre o tradutor a já repetida, ad nauseam, máxima italiana, em forma de jogo de palavras, que diz "traduttore, traditore" ("tradutor, traidor"), pois todo tradutor teria de trair o texto original para conseguir reescrevê-lo na língua desejada. Entretanto, pode-se garantir que, em se tratando de texto filosófico, a traição ocorrerá a partir do instante em que as ideias do autor do texto original forem distorcidas ou contrariadas no texto traduzido, ou seja, se ao comparar o nível e compreensão dos leitores das duas 
Julião, J. N.

línguas for observado que há divergência quanto à compreensão das ideias. Nesse sentido, Itaparica não é traditore - como muito em voga, em todos os âmbitos da nossa cultura -, mas um traduttore e isto ocorre devido ser ele um conhecedor das duas línguas em jogo na tradução, o alemão e o português, além de ser um estudioso da filosofia de Nietzsche e, no caso específico do texto traduzido, eu diria, um perito, bastante familiarizado com os termos e temas nietzschianos ali expostos.

Resenha recebida para publicação em 10/03/2017.

Resenha aceita para publicação em 15/06/2017.

$186 \mid$ Cad. Nietzsche, Guarulhos/Porto Seguro, v.38, n.2, p. 179-186, maio/agosto, 2017. 